\title{
Nitinol-frame artificial trachea: Knight in shining armor or wolf in sheep's clothing
}

\author{
Jules Lin, MD
}

\author{
From the Section of Thoracic Surgery, Department of Surgery, University of Michigan Medical Center, Ann Arbor, Mich. \\ Disclosures: Author has nothing to disclose with regard to commercial support. \\ Received for publication April 28, 2018; revisions received April 28, 2018; accepted for publication May 1, 2018; \\ available ahead of print June 19, 2018. \\ Address for reprints: Jules Lin, MD, Section of Thoracic Surgery, 1500 E Medical Center Dr, 2120TC/5344, Ann \\ Arbor, MI 48109-5344 (E-mail: juleslin@umich.edu). \\ J Thorac Cardiovasc Surg 2018;156:1263 \\ $0022-5223 / \$ 36.00$ \\ Copyright $(2018$ by The American Association for Thoracic Surgery \\ https://doi.org/10.1016/j.jtcvs.2018.05.013
}

Sakaguchi and colleagues ${ }^{1}$ describe an artificial nitinol-frame trachea and believe that this novel construct shares physical characteristics with the native trachea. However, it is unclear if the force measurements of the symmetric tubular nitinol construct - with equal forces in all directions - are comparable to asymmetric native trachea because the measurements were only taken in 1 dimension (ie, anterior cartilaginous to posterior membranous airway) and how that compares with forces in the other dimension (ie, cartilaginous to cartilaginous airway).

The authors ${ }^{1}$ state that the nitinol construct reproduces the shape of the native trachea, although the nitinol stent is circular, whereas the native tracheal rings are $\mathrm{C}$-shaped with a membranous portion posteriorly, allowing the trachea to deform when coughing to clear mucous. How well does the circular nitinol construct deform when coughing? Would a decellularized tracheal graft provide a more natural shape and better mucous clearance ${ }^{2}$ In addition, although the tracheal construct was re-epithelialized with a monolayer of epithelial cells, it is unclear if this monolayer is as effective at mucous clearance as the ciliated stratified epithelium of native trachea.

The preliminary results are interesting; however, only a short $2-\mathrm{cm}$ portion of the trachea was resected, a length that is routinely resected with primary anastomosis. The technique described would be most useful for longer resections that cannot be performed with a primary anastomosis. How could differences in a longer construct influence epithelialization, angiogenesis, and mucous clearance?

Complete epithelialization is important in preventing granulation and stenoses. Epithelialization occurred from the native trachea over 3 months. Longer constructs could take a prolonged period to epithelialize, potentially leading to increased rates of ulceration and stenoses. In a previous article from this group, ${ }^{3}$ the atelocollagen layer was seeded with stem cells. Would seeding the collagen layer with epithelial cells and/or mesenchymal stem cells increase the rate of epithelialization? ${ }^{4}$ Growth factors may also be important, and decellularized grafts remain biologically active with extracellular matrix, chemotactic growth factors, and pro-angiogenic factors. The authors found that angiogenesis occurs 2 months after tracheal implantation with vessels extending from the native trachea and not from the omentum. With longer resections, it is unclear if the

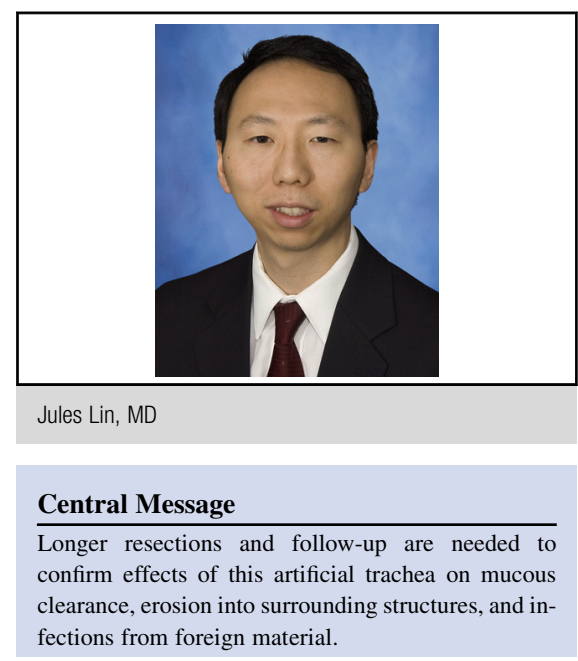

See Article page 1264.

midportion of the tracheal construct will be relatively more ischemic and prone to stenoses.

Although the authors ${ }^{1}$ provided intermediate-term results, it will be important to have longer-term follow-up to determine the effect of a nitinol-frame artificial trachea on surrounding structures because chronic metallic stent placement has been associated with erosion. ${ }^{5}$ Long-term follow-up will also be necessary to determine whether there is an increased risk of infectious complications with incorporation of foreign material into the tracheal wall.

The authors ${ }^{1}$ describe a novel artificial tracheal construct in a canine model. Although the results are interesting, longer resections and follow-up are needed to confirm the effects of this artificial trachea on mucous clearance, erosion into surrounding structures, and infections from foreign material and to determine whether the nitinol-frame artificial trachea is truly a knight in shining armor or a wolf in sheep's clothing.

\section{References}

1. Sakaguchi Y, Sato T, Muranishi Y, Yutaka Y, Komatsu T, Omori K, et al. Development of a novel tissue-engineered nitinol frame artificial trachea with native-like physical characteristics. J Thorac Cardiovasc Surg. 2018;156:1264-72.

2. Ohno M, Fuchimoto Y, Hsu HC, Higuchi M, Komura M, Yamaoka T, et al. Airway reconstruction using decellularized tracheal allografts in a porcine model. Pediatr Surg Int. 2017;33:1065-71.

3. Nakamura T, Sato T, Araki M, Ichihara S, Nakada A, Yoshitani M, et al. In situ tissue engineering for tracheal reconstruction using a luminar remodeling type of artificial trachea. J Thorac Cardiovasc Surg. 2009;138:811-9.

4. Go T, Jungebluth P, Baiguero S, Asnaghi A, Martorell J, Ostertag H, et al. Both epithelia cells and mesenchymal stem cell-derived chondrocytes contribute to the survival of tissueengineered airway transplants in pigs. J Thorac Cardiovasc Surg. 2010;139:437-43.

5. Katsanos K, Sabharwal T, Koletsis E, Fotiadis N, Roy-Choudhury S, Dougenis D, et al Direct erosion and prolapse of esophageal stents into the tracheobronchial tree leading to life-threatening airway compromise. J Vasc Interv Radiol. 2009;20:1491-5. 